This is the accepted version of an article published by Elsevier in Energy Policy Vol. 113 (2), 559-570. Published version available from: https://doi.org/10.1016/j.enpol.2017.11.046

Accepted version made available from SOAS Research Online under CC-BY-NC-ND 4.0 International License at: http://eprints.soas.ac.uk/24931/

\title{
Green Transition of Energy Systems in Rural China: National Survey Evidence of Households' Discrete Choices on Water Heaters
}

\author{
Ben Ma \\ School of Environment and Natural Resources, Renmin University of China \\ Beijing, 100872, China; Email: mbruc@,163.com \\ Yihua Yu (Corresponding Author) \\ Department of Energy Economics, Renmin University of China \\ Beijing, 100872, China; Email: vihua.yu@,ruc.edu.cn
}

\section{Frauke Urban}

Centre for Development, Environment and Policy CeDEP, SOAS, University of London London, WC1H 0XG, UK; Email: f.urban@soas.ac.uk

\begin{abstract}
Energy systems in rural China are experiencing a transition from traditional fossil fuels to renewables. This paper aims to investigate the potential factors that influence the choices of rural residents regarding water heaters with a focus on the low-carbon transition to solar water heating systems. To this end, a face-to-face questionnaire survey is undertaken with 3404 rural households randomly selected among 12 representative provinces. A comprehensive set of discrete choice modelling approaches were used. The empirical results show that (1) sociodemographic variables have significant effects on residents' first-stage choice of a water heater (to buy or not to buy) but few effects on the second-stage decision to choose electric, LPG, or solar water heaters (which type to buy); (2) information spillover is important to facilitate the usage of water heaters, particularly of solar products; (3) the electricity price, which is regulated at a very low rate, has no apparent effect on the choice of solar water heaters; (4) government subsidy has a significant effect in the first stage but no differentiated effect on the decision choice in the second stage. Policy and managerial implications are presented to speed up the ongoing low-carbon transition of energy systems in China.
\end{abstract}

JEL classifications: O13, Q42, R22, C25

Keywords: Water heater; Consumer behaviour; Renewable energy; Discrete choice model; Rural China 


\section{Introduction}

As China continues on a path of rapid economic growth, it faces rising environmental challenges, including worsening air pollution and the threat of climate change, evidenced by the fact that China is the world's biggest carbon dioxide emitter, producing each year roughly the equivalent of the US and the European Union combined (Liu, 2015). To address these concerns, the country has begun implementing ambitious programmes in renewable energy and energy efficiency in recent years (Ma et al., 2014; Zhu et al., 2015). These programmes include the national milestone Renewable Energy Law, which took effect in January 2006, the national Medium- and Long-Term Development Renewable Energy Plan, launched in September 2007, and the Medium- and LongTerm Energy Conservation Plan launched in November 2004. Upscaling the development and deployment of renewable energy is also strongly supported by China's recent Five Year Plans, such as the $13^{\text {th }}$ and the $12^{\text {th }}$ Five Year Plans. Through these efforts, China hopes to improve its energy supply and energy security, enhance the quality and competitiveness of its economy, reduce pressure on the environment, and mitigate the effects of climate change. Meanwhile, the Chinese government has ramped up investment in low-carbon energy and put in place a growing array of climate and energy policies. For example, in 2015, China set its low carbon energy targets for nonfossil fuels to generate $20 \%$ of total primary energy by 2030 (Xinhua Net, 2015).

However, China's rising demand means new fossil fuel capacity is added continuously: the overall share of renewables within the total energy supply is stagnating at best, despite impressive investments in low-carbon energy technology and a wide array of climate and energy policies. In fact, China is investing more than any other country in the world in renewable energy, including hydropower, wind energy, and solar energy (Zeng et al., 2014). In China, 85 million solar water heating systems have been installed and can be found in every province (Urban et al., 2016). Yet, solar water heaters are still far from mainstream. There is huge potential and an as-yet underexploited market. China's approach to solar energy has mainly focused on large-scale technologies and interventions such as large-scale ground-mounted solar photovoltaic (PV) farms and concentrated solar power. However, a small-scale technology has made a significant contribution that goes largely unnoticed. Domestic solar water heaters are ubiquitous and massively successful in China: they are the rarely-mentioned champion of low-carbon energy (Urban et al, 2016).

Since solar water heaters are useful tools for achieving a low-carbon society in China, this study aims to examine how Chinese consumers choose water heaters, and in particular what drives consumers to purchase solar water heaters. To tackle this issue, a face-to-face questionnaire survey of 3404 rural households randomly selected among 12 representative provinces was undertaken. By examining consumers' choices of electric, liquefied petroleum gas (LPG), and solar water 
heaters, a comprehensive set of discrete choice modelling approaches (both multinomial logit model and nested logit model) were used. It is worth mentioning that rural China does not have natural gas pipelines installed, hence, natural gas is not used to provide hot water in rural China, but is a common type in many OECD countries. According to our survey, the leading purpose of installing a water heater is for showers in rural China. Nearly $97.0 \%$ of the respondents of our survey considered showers as the primary usage. Other primary usages include cleaning the kitchen $(1.7 \%)$, space heating $(0.3 \%)$, and heating feed for livestock $(0.4 \%)$. This is consistent with the situation reported by Yuan et al. (2011), whose survey revealed that showers, cleaning, and laundry accounted for $82.1 \%$ of hot water usage by solar water heaters in China.

The empirical results show that (1) sociodemographic variables such as income level, household size, and homeowner age have significant effects on residents' first-stage choice of a water heater (to buy or not to buy) but no effects on the second-stage choice (which type to buy); (2) information exchange between rural and urban areas is important to facilitate the usage of water heaters, particularly of solar products for rural residents; (3) electricity price has no apparent effect on the choice of solar water heater because it is highly regulated at a very low rate and keeps unchanged for years; (4) government subsidy exerts a significant effect in the first stage but has no differentiated effect on the choice of the three types of water heaters in the second stage. Policy implications for promoting low carbon solar water heaters and green transition of energy system in rural China are drawn from this empirical study.

This study is novel in that, compared with the large amount of literature targeting mainly European and American countries, quantitative studies of consumer choice regarding energy appliances in China are rather limited. Particularly, largely due to a lack of data, no study has investigated the research topic on water heaters in rural China. This study is intended to fill a gap in the literature by examining Chinese data from a household survey. An additional merit of our analysis is that we applied a series of logit models to examine two related issues: The first is the determinants of a binary outcome of using versus not using water heaters (to buy or not to buy), which does not appear to be a relevant issue in the developed countries because water heating or residential space heating systems are widely used in these countries in people's daily lives. In rural China, however, the installation ratio of water heaters is low (only 34.05\% in rural China) and hence usage or non-usage of a particular appliance is an issue of high relevance. The second issue is the determinants of multinomial choices of water heaters (which type to buy), facilitating policy implications for promoting solar water heaters and the green transition of energy systems in rural China. Another advantage of this study is that we take into consideration two novel variables in the empirical models, namely the travel frequency of family members of the surveyed respondent 
and the distance between the respondent's place of residence and the nearest town or urban centre. As we hypothesize that rural households' decision-making could be affected by knowledge spillovers through social interactions in urban areas, this study attempts to shed some light on the likelihood of spatial interaction effects on rural consumers' choices of water heaters.

The structure of this study is organized as follows. Section 2 reviews relevant studies on residents' choices regarding the adoption of electric appliances or solar products. Section 3 describes the empirical modelling techniques used to address the determinants of consumer choices regarding different water heaters. Section 4 introduces the questionnaire design and data collection issues, and the empirical results are reported in Section 5. Section 6 discusses some policy implications for promoting energy-efficient solar water heaters in China. The last section concludes this study and comments on some potential limitations of the present study as well as suggests options for future research.

\section{Literature review}

Various scholars have examined, theoretically or empirically, residential choices regarding electric appliances and energy at national, state, and local levels. In general, existing studies can be broadly classified into the following three strands.

Research objectives: studies regarding residential choices on electric appliances focus mainly on the consumers' choices of household space heating equipment (Braun, 2010; Decker and Menrad, 2015; Michelsen and Madlener, 2012, 2013, 2016; Ruokamo, 2016), air conditioners and refrigerators with different energy efficiency labels (Shen and Saijo, 2009), and willingness to pay for renewable energy technologies like solar PV, micro-wind, solar thermal, heat pumps, biomass boilers, and pellet stoves (Scarpa and Willis, 2010). For instance, Braun (2010) focused on the determinants of the heating mode choices in Germany. The results implied that regional effects and dwelling features are important for heating system choices. Michelsen and Madlener (2012, 2013, 2016) examined space heating choices of German homeowners. Specifically, Michelsen and Madlener (2016) analysed data from a 2010 questionnaire survey among owners of existing singlefamily and duplex houses that had received financial grants to install (partly) renewable residential heating systems (i.e. condensing boiler with solar thermal support, heat pump, or wood pellet boiler). They show that environmental protection, a lower dependency on fossil fuels, and a higher degree of residential heating system-related knowledge are key drivers.

In contrast, studies on households' hot water systems are scant. By applying the mixed and nested logit models, Goto et al. (2011) examined how consumers select ecologically efficient water heaters in Japan. They mainly found that energy price is an important determinant of consumers' 
choices of energy-efficient appliances. Using a discrete choice experiment, Wasi and Carson (2013) studied the switching behaviour of New South Wales homeowners from electric water heaters to more environmentally friendly versions like solar water heaters targeted by hot water system rebate programmes and they evaluated the effectiveness of the programmes. Since this kind of analysis relies heavily on the availability of microdata, to date, no studies were found on discrete choices of households regarding water heaters in China.

Research areas: household's appliance choice studies in the developed countries, especially Germany, represent by far the largest share of the relevant literature. These include studies by Braun (2010), Decker and Menrad (2015), and Michelsen and Madlener (2012, 2013, 2016) in Germany, Gill et al. (2015) and Wasi and Carson (2013) in Australia, Goto et al. (2011) in Japan, Ruokamo (2016) in Finland, Scarpa and Willis (2010) in the UK, and Dubin and McFadden (1984) and Liao and Chang (2002) in the US. Being the most economical, mature, and popular renewable technology (Chang et al., 2009; Han et al., 2010), solar water heaters have been the topic of several studies in China. This line of studies mainly focused on several relevant aspects of the deployment of this renewable technology and different innovation paths (Urban et al, 2016). Different aspects of the deployment include social acceptance and public awareness of solar water heaters (Yuan et al., 2011), economic feasibility analysis of diffusion of solar water heaters (Han et al., 2010; Li et al., 2011; Ma, et al., 2014), institutional analysis of factors to make solar water heating systems successful (Li et al., 2011; Goess, et al., 2015), and evaluations of incentive programmes (Chang et al., 2011, 2016; Ma et al., 2014). These studies tend to examine some inherent characteristics of the solar products, but fail to model the possible substitution relationships and consumers' preferences among kinds of water heaters. To the best of the authors' knowledge, no previous study has explored the research subject on choices between various water heaters in China.

Choice determinants: the literature references a number of studies on residential choices regarding electric appliances and solar energy, which are determined by sociodemographic factors (i.e., income, age, education, etc.), dwelling characteristics (i.e., building area, age, and location factors), price factors (i.e., energy prices), and policy factors (i.e., subsidies for solar water heater purchases) (Braun, 2010; Decker and Menrad, 2015; Goto, et al., 2011; Michelsen and Madlener, 2012, 2013). These studies, mainly in the context of high-income countries, provided important insights for our analysis on rural households' choices of water heaters in China. Some issues, however, still need to be highlighted and resolved since the situation is distinct, especially in China's rural areas, at least in the following aspects. First, income is not found to be the major factor in choosing a highefficiency, low-carbon product in Germany (Braun, 2010; Michelsen and Madlener, 2013). A possible reason is that income levels are relatively high in Germany and are therefore not a 
constraint in the purchase of low-carbon products. In contrast, the income level is relatively low in rural China. Second, energy price plays an important role in influencing consumers' choices of water-heating products in Japan (Goto et al., 2011), but residential electricity prices are regulated at a very low rate and keep stationary for years in China. Third, the developed countries already have a high rate of ownership of home appliances and their focus has been turning to the replacement of low-efficiency (high-carbon) equipment with high-efficiency (low-carbon) products. For instance, $95.0 \%$ of the owner-occupied houses have a heating system installed in developed countries (Braun, 2010), and Australia is at the stage of switching from electric water heaters to solar water heaters (Wasi and Carson, 2013). However, the installation rate of water heaters in rural China remains low, and determinants of consumers' decision choices in China can be different from those in the developed countries. To sum up, there are evident differences between residents in China and Western countries regarding purchasing decisions on electric appliances, justifying our further investigation of choices of shower water heaters in the context of China.

\section{Methodology}

In this section, we first describe the multinomial logit model and then the nested logit model.

\subsection{A multinomial logit model}

We start with an unobserved continuous latent variable $y^{*}$ such that $y^{*}=x \beta+\varepsilon$, where $x$ is a vector of explanatory variables, $\beta$ is a column vector of coefficients, and $\varepsilon$ is the error disturbances. We recognize that $y^{*}$ is not observable, yet we do observe a realization in the form of a binary dependent variable $y$ such that $y=1$ if $y^{*} \geq 0$ and $y^{*}=0$ if $y^{*} \leq 0$. We aim to estimate the probability of success, $p$, which is written as:

$$
\begin{aligned}
p=\operatorname{Pr}(y=1 \mid x) & =\operatorname{Pr}\left(y^{*} \geq 0 \mid \mathrm{x}\right)=\operatorname{Pr}(x \beta+\varepsilon \geq 0 \mid x) \\
& =\operatorname{Pr}(\varepsilon \geq-x \beta \mid x)=1-F(-x \beta)=\mathrm{F}(x \beta),
\end{aligned}
$$

where $\operatorname{Pr}$ stands for probability and $F$ is the cumulative distribution function of the error terms, which is usually assumed to follow either the logistic or normal distribution, both of which are $S$ shaped curves. For the logistic model, Eq. (1) can be rewritten as: $p=1-1 /\left(1+e^{x \beta}\right)=1 /\left(1+e^{-}\right.$ $\left.x^{x}\right)$, whereas for the probit model resulting from the normal distribution, Eq. (1) can be rewritten as $p=1-\Phi(-x \beta)=\Phi(x \beta)$. The marginal effect of a particular variable is derived as: 
$\partial p / \partial x_{k}=f(x \beta) \beta_{k}=e^{x \beta} \beta_{k} /\left(1+e^{x \beta}\right)^{2}$ (logit case), or $\Phi(x \beta) \beta_{k}$ (probit case),

where $f$ represents the probability density function. Equation (2) shows that the marginal effect is nonlinear and will depend on not only the coefficient of the variable of interest $\left(\beta_{k}\right)$ but also the chosen distribution $F$ and the values of all of the explanatory variables $(x)$. This result is thus different in several ways from the traditional ordinary least square model, where the marginal effect is constant. To estimate either the logit or probit regression model and the marginal effects, we use the maximum likelihood estimation (MLE) method, which produces consistent and asymptotically efficient estimators. The empirical results from both models tend to be very similar, and preference for one over the other tends to vary with discipline.

The next task is related to examining the determinants of the probability that an individual will choose a specific water heater from a choice set of more than two alternatives [electric water heater, liquefied petroleum gas (LPG) water heater, solar water heater, etc.], given that he or she has already made a choice to purchase a water heater. Therefore, the multinomial logit, having more than two unordered choices for the dependent variable, can actually be considered an extension of the binary logit model as mentioned above. The multinomial logit model is treated as a random utility model (McFadden, 1978), where $U$ (choice $j$ for individual $\imath$ ) $=U_{i j}=V_{i j}+\varepsilon_{i j}$, where the utility level $U_{i j}$ is determined by the systematic component of utility $V_{i j}$, and the random disturbance term $\varepsilon_{i j}$, which is assumed to be independently and identically distributed with a Gumbel distribution. Utility maximization implies that the probability of an individual $i$ choosing a particular water heater $j$ is determined by $p_{i j}=\operatorname{Pr}\left(U_{i j}>U_{i k}\right)$ for $k \neq j$. For the multinomial logit model, $p_{i j}=e^{\beta_{j}^{\prime} x_{i}} /\left(1+\sum_{k=1}^{J} e^{\beta_{k}^{\prime} x_{i}}\right)$ for $j=1,2, \ldots, J$, where $\beta$ s is a vector of parameters to be estimated. The normalization $\beta_{1}=0$ should be imposed in order to identify the parameters of the model. The marginal effect of a particular variable is $\frac{\partial p_{i j}}{\partial x_{i}}=p_{i j}\left(\beta_{j}-\sum_{k=0}^{J} p_{i k} \beta_{k}\right)$. Similarly to that for the binary case, the marginal effect in the multinomial logit model depends not only on the coefficient estimate $\beta_{j}$ but also on all the other coefficient estimates and variables. It is worth mentioning that one important assumption of the multinomial logit model is the independence from irrelevant alternatives (IIA). The IIA assumption implies that introducing another alternative will have the same proportional effect on the probability of each alternative. In order to examine such an assumption, a Hausman-McFadden test (Hausman and McFadden, 1984) or Small-Hsiao test (Small and Hsiao, 1985) can be applied. 


\subsection{A nested logit model}

The multinomial logit model is usually criticized for the IIA property of unobserved random error terms $\varepsilon_{i j}$, which are assumed to be independently and identically distributed (Train, 2009), or in other words, the alternatives (choices) are assumed to be independent of one another. To model individual behaviour, it is likely that the IIA assumption will be violated if individuals perceive the heating alternatives as close substitutes. For instance, if individuals perceive the attributes of the solar heater and solar-electricity heater as similar, then the unobserved impact factors that affect one heater may also affect another. If there is unobserved correlation among the alternative choices, the multinomial logit model will be improperly specified and will generate parameter estimators that are inconsistent (Greene, 2011). To remedy the IIA assumption to the greatest extent possible, the nested logit model is a proper method of estimation which embeds alternatives with correlated error terms in a nest. In this study, one possible nest structure is to group households that use shower water heater in a group and those that do not in another group in the first stage (Fig. 1); in the second stage, people who use shower water heaters may choose solar water heaters (renewable energy heating system) LPG water heaters, or electric water heaters (traditional heating systems).

The probability of choosing alternative $j$ from nest $k$ is derived by multiplying the probability of selecting nest $k$ by the conditional probability of choosing alternative $i$, that is, $\operatorname{Pr}(\operatorname{twig} j$, branch $k)=p_{j k}=p_{j \mid k} \times p$. In such a two-level nested logit model, $p_{j \mid k}=e^{\beta x_{j \mid k}} / \sum_{j=1}^{J_{k}} e^{\beta x_{j \mid k}}, p_{k}=$ $e^{\gamma z_{k}+\tau_{k} I_{k}} / \sum_{k=1}^{K} e^{\gamma z_{k}+\tau_{k} I_{k}}$, where $I_{k}=\ln \sum_{j=1}^{J_{k}} e^{\beta x_{j \mid k}}$ for the kth branch, among which $x$ varies over both branches and twigs and z varies over twigs only. The term $I_{k}$ is known as the inclusive value or a $\log$-sum. The scale parameter $\tau$ measures the correlation among the random error terms $\left(\varepsilon_{j k}, \varepsilon_{j l}\right)$ due to unobservable attributes of lower level choices (i.e., twig choices). Again, MLE is used to estimate the nested logit model.

\section{[Insert Figure 1 about here]}

\section{Survey and data}

In this section, we first introduce the survey design followed by the survey process and then describe the empirical data to be used in this study.

\subsection{Survey design and process}

The data used for this study are taken from the Chinese Residential Energy Consumption Survey 
(CRECS), which was implemented during the summer period (July and August) in 2014. This round CRECS survey focus only on rural household energy consumption, while the first round survey launched in 2012 targeted at both urban and rural households. The Department of Energy Economics at Renmin University of China designed the questionnaire that has been amended from the US Department of Energy, more specifically the Energy Information Administration Residential Energy Consumption Survey. The questionnaire covered six main areas with 324 questions about rural household's consumption status in 2013, which included household characteristics, dwelling characteristics, household appliances, space heating and cooling, patterns of private transportation, and electricity billing, metering, and pricing options.

After finishing the design of the questionnaire, we sent it to the National Survey Research Center (NSRC) at Renmin University of China who is in charge of sample selection. Given the time and budget constraints, we decided to give up sampling all provinces in China. Instead, we invited scholars with backgrounds or experience in energy economics, agriculture economics, statistics, and field survey to discuss proper sampling selection strategy, and eventually selected 12 representative provinces that vary substantially in terms of energy types, spatial location, climatic conditions and socioeconomic indicators (Wu et al., 2017). These provinces include Hebei, Heilongjiang, Jiangsu, Zhejiang, Fujian, Hubei, Hunan, Guangdong, Sichuan, Yunnan, Shaanxi, and Gansu.

In terms of sampling procedures, the samples were selected using a combination of probability proportional to size (PPS) and multi-level random sampling techniques. The sampling procedures include three steps. In the first step, county-level units, which include counties (xian) and countylevel cities ( $x i a n j i$ shi), were first ascertained as the primary sampling units (PSUs), then using a PPS sampling technique, we identified 65 PSUs in these 12 representative provinces. In the second step, 65 villages were selected as the secondary sampling units (SSUs). We randomly selected one village within each county. In the third step, households were the tertiary sampling units (TSUs). In this step, 60 households were randomly selected from each SSU using the Kish sampling method. ${ }^{1}$ From each household, one person aged over 18 was selected to conduct the face-to-face interview. This sampling procedure yields a sample of 3900 rural households in 65 county-level units or villages (i.e., SSUs or TSUs) across 12 provinces that should be surveyed. The sampling distribution is mapped in Fig. 2.

Last, it is the job of the Youth League of Renmin University to recruit interviewers, who will be provided with a two-day training lecture by the Department of Energy Economics, and will conduct a face-to-face personal interview with the respondent for approximately 1 to 1.5 hours. Excepting designing the questionnaire and training the interviewers, the Department of Energy 
Economics is also responsible for controlling data quality. For more details on the energy survey design, sampling and implementation, data quality control, and sample representativeness, the reader is referred to the publications by Wu et al. (2017), Yu and Guo (2016), and Zheng et al. (2014). As mentioned, the survey process should survey 3900 rural households. After data cleaning and removing invalid samples, we obtain a valid sample of 3404 observations.

\subsection{Data description}

In general, there are four types of factors $(x)$ considered to influence whether the surveyed individual chooses a water heater $(y)$. The first type of factor is the individual's social and demographic characteristics such as age, gender, per capita income, and education level. The second type is the price of each energy type like electricity, LPG, and other fossil fuels. The third type includes housing characteristics such as the location of the house of the surveyed individual. The last type is incentive policies, particularly to promote low-carbon water heaters such as solar products.

Because of some market and non-market barriers such as a lack of information on available technologies and limited access to capital, an energy efficiency gap occurs, taking the form of underinvestment in energy efficiency relative to a description of the socially optimal level of energy efficiency (Allcott and Greenstone, 2012; Gillingham et al., 2009). For example, inadequate information, high investment risk, and the high up-front cost of solar water heaters may hinder their application in rural China. In the survey form, we include six categories of explanatory variables: sociodemographic characteristics, information exchange, lifestyle habits, natural resources, energy prices, and policy variables. Table 1 presents the structure of the survey, definition of variables, and theoretical basis of the selection of variables.

\section{[Insert Table 1 about here]}

Table 2 provides a list of these variables and reports descriptive statistics of the samples. As reported by Yuan et al. (2011), who conducted a survey in Ji'nan, Shandong province in 2010, public awareness of solar water heaters is much lower among people older than 60 than among people in other age groups. Thus, we use a dummy variable taking a value of 1 if the homeowner is older than 60 . For energy-saving awareness, we use a binary category variable by setting it to 1 when a household uses at least one inefficient incandescent bulb. The underlying logic is that energy-saving awareness is much lower in households still using filament lamps when sunlight or energy-saving lamps are widespread in rural China. The educational level variable is formed by 
setting the binary value to 1 when the homeowner has not experienced formal education. We also introduce a dummy to represent the travel frequency of a family by setting the value to 1 if the total number of trips per year is between 1 and 5 . Likewise, we set the binary value to 1 when households are located within $1 \mathrm{~km}$ of a town centre and 0 otherwise.

In general, China has abundant solar energy. The solar radiation zone with more than 2200 sunshine hours covers about $67 \%$ of the country's land area (Liu et al., 2010). In this study, we use a dummy as a proxy for the solar resources received by each household. According to the zoning of solar radiation in a national feed-in tariff for PV power generation (NDRC, 2013), we set the value to 1 if a household is located in Class I or II (with abundant radiation) and 0 otherwise. The value of the policy variable is defined as 1 if a subsidy is available when households make a purchase. The subsidy available for rural residents in China primarily refers to the "Home Appliances Going to the Countryside" programme, which was in effect from 2009 to early 2013.

The remaining variables such as income, family size, air temperature, and energy prices have continuous or discrete values as listed in Table 2 . For instance, $44.84 \%$ of surveyed households earned more than 8000 yuan per capita in 2013. In rural China, two-person households are the most common, making up of $37.95 \%$ of the total. Compared with the variation of LPG prices, the price of electricity presents only a small change among the surveyed households. In addition, we introduce regional dummies to control for regional heterogeneity in terms of unobserved factors such as consumption culture. For households located in Guangdong, Fujian, Jiangsu or Zhejiang, we create dummy east, while for families in Gansu, Shaanxi, Sichuan or Yunnan, another dummy west is added.

According to our survey, the coverage rate of shower water heaters (which is defined as the ratio of the number of households installing shower water heaters to the total number of households surveyed) in rural China is 34.05\% in 2013 (Fig. 3). The figure is fairly reasonable compared to the official statistic of 40.8\% released for the year 2012 (Fig. 4).

According to Fig. 3, the coverage rate of solar water heaters in rural households in China reached only $16.92 \%$ in $2013{ }^{3}$ This rate is much lower than that in urban China. For example, Li et al. (2011) reported that the coverage rate of solar water heaters in urban Dezhou (Shandong Province) reached $75.4 \%$ in 2010 , and another investigation revealed that it amounted to $94.3 \%$ in the urban area of Haining in Zhejiang Province in 2006 (Han et al., 2010). However, these are the two provinces that have the highest deployment rates of solar water heaters in China, while other provinces have far lower rates.

[Insert Table 2 about here] 


\section{[Insert Figure 2 about here]}

\section{[Insert Figure 3 about here]}

\section{Empirical results}

In this section, we report first the empirical results from the multinomial logit model and then the results from the nested logit model. To treat with possible error correlation among households in the same village, we employ village cluster standard error technique to run the following models.

\subsection{The multinomial logit model}

We first use a multinomial logit model to test the determinants of the purchase decision making regarding water heaters by rural residents in China. The independent variables can be grouped into sociodemographic characteristics, information exchange, lifestyle habits, natural resources, energy price, policy variable, and the regional variable. As reported in Table 3, we mainly focus on the selection of three types of water heaters, that is, electric, LPG, and solar water heaters. Treating families without installed water heaters as a base category, the estimation results are listed in Columns 3 to 5 in Table 3. In subsequent columns, the electric water heater (Columns 6 and 7) and LPG water heater (Column 8) are used as the base categories, respectively. It is worth mentioning that only 1757 observations are used in the regression analysis due to missing data for the income, education, distance, and LPG price. We performed a nonparametric Mann-Whitney test on several variables such as water-heater usage, family size, energy-saving, distance and electricity price for these two subsamples (included and exclude). In general, we find no evidence of systematic difference between these two subsamples, implying the empirical econometric models with some missing data dropped from the regression may not suffer from sample selection bias problem and the current sample used is fairly representative.

For sociodemographic characteristics, we find that factors such as income, family size, and age of home owner matter in families' purchasing decisions on water heaters. Household income per capita can exert a significant positive impact on the deployment decision of a rural household. The coefficients of income are positive for all three types of water heater, indicating that the probability of water heater usage of any type will increase as family income rises. Specifically, when income rises by 1000 Chinese yuan per year, the log-odds ratio of the LPG water heater versus the base case (i.e., no installation) will increase by $6.42 \% .{ }^{4}$ The coefficients of the electric and solar water heaters are 2.66 and $2.12 \%$, which are much smaller than that of the LPG alternative. Compared to households with electric water heaters, a higher income will increase the chance of deployment 
of an LPG water heater $\left(0.0376^{* *}\right)$, while the probability of solar water heater usage will not increase (-0.00534). In terms of family size, the significance of coefficients is fairly similar to the income case. When a family has an additional member, the log-odds ratio of LPG water heater usage versus non-usage will increase by $45.6 \%$. In the electric and solar cases, the coefficients are 22.5 and $16.0 \%$, respectively. However, the coefficients for age are quite distinct. If the age of the homeowner exceeds 60 years, the probability of LPG and solar water heater installation drops substantially, with coefficients of -1.032 and -0.530 , respectively. Neither awareness nor education has a significant impact on the purchase behaviour.

Information exchange is relevant in the purchase decisions of rural residents regarding solar water heaters. Although the frequency of travels to city areas per year seems to be irrelevant for usage of the three types of water heaters, households have a higher tendency, compared to those who do not install water heaters, to install solar water heaters when the household is located within $1 \mathrm{~km}$ of the nearest town centre (the coefficient is $0.711^{* *}$ ). However, the effects are not significant in statistics for either electric water heater or LPG water heater (the coefficients are 0.488 and 0.395, respectively).

Regarding lifestyle habits, we find that air temperature is a significant determinant. With a higher temperature, residents in rural areas tend to install more LPG water heater and solar water heaters compared to families without any water heaters $\left(0.606^{* * *}\right.$ and $\left.0.184^{* *}\right)$. This simply reflects the fact that people living in warmer area are more likely to install a water heater so as to take a shower. However, the usage of electric water heater is insensitive to air temperature. One possible explanation is that rural residents in cold zones can use electric heaters to raise air temperature of bathroom at night, making shower at home feasible.

Households living in regions with high solar radiation are found to have a higher but insignificant probability of deploying a solar water heater (0.514). This finding implies that solar resource is typically not a constraint for rural residents in China to deployed solar water heaters. According to our survey, the coverage rate of solar water heater reaches $14.9 \%$ (83 out of 557 households surveyed) in Sichuan Province, a province with the least solar radiation in China (Ma et al., 2014). The coverage rate of solar water heater is much higher than that of electric water heater in Sichuan $(6.1 \%$ for electric water heater, 34 out of 557 households). In addition, households situated in areas with rich solar radiation will have more chance to deploy a solar water heater compared to a LPG product (13.25***), which seems to be fairly reasonable.

In contrast to families without water heaters, a higher electricity price reduces the probability of a household installing an electric water heater $\left(-0.0933^{*}\right)$. This is reasonable since a higher price pushes up the operating costs of a water heater fuelled by electricity. Further, we find that a higher 
electricity price increases the probability of a household using an LPG heater $\left(0.103^{* *}\right)$. However, a higher electricity price does not increase the probability of using a solar water heater $\left(-0.200^{* * *}\right)$, indicating that an LPG water heater is more likely to be a better alternative to an electric water heater. The coefficient of LPG price is typically insignificant, implying that the LPG price is not an important factor for rural residents in selecting a water heater. A basic fact is that the usage of LPG water heater is unpopular in rural China, with a coverage rate of only $4.29 \%$. The primary usage of LPG in rural China is cooking instead of showering.

With regard to the policy variable, the coefficients are generally significant when families without water heaters are treated as the comparison group. The subsidy as a part of the "Home Appliances Going to the Countryside" programme can promote the probability of installation of all three types of water heaters $\left(20.89^{* * *}, 19.24 * * *\right.$ and $\left.20.31^{* * *}\right)$. The effect on electric water heaters is typically larger than that on their LPG or solar alternatives. The policy effects are $-1.651^{* * *}$ and $-0.573^{* * *}$ for LPG and solar water heaters compared to an electric product. The policy effect is more evident for solar water heaters than in the LPG case $\left(1.078^{*}\right)$.

For the empirical findings from the multinomial logit model to be valid, the IIA assumption must be held. This assumption forces the odds of choosing one alternative over another to be independent of the other alternatives. We run both Hausman-McFadden tests and Small-Hsiao tests to test the IIA assumption for each possible omitted category. ${ }^{5}$ The Hausman-McFadden tests, at the conventional 5\% level of significance, suggested that the odds are dependent on other alternatives for all four choices (including non-usage and electric, LPG, and solar water heaters). However, according to Small-Hsiao tests, the independence of non-usage is supported, while the use of the three types of water heaters is dependent on one another.

Thus, it is necessary to further run nested logit models for several reasons. First, the nested logit models relax the strict assumption that each alternative is independent of the others. Second, the residents' choices regarding water heaters in rural China exhibit a clear two-stage structure. The first decision is whether or not to purchase a water heater, and the second is the choice of one of the three products to finish the whole decision process. Third, if the estimation results by the multinomial and nested logit models are consistent, this cross-checking strategy can confirm the robustness of our main findings.

\section{[Insert Table 3 about here]}




\subsection{The nested logit model}

We first cluster all explanatory variables into two groups. The first group mainly determines whether a household will decide to install a water heater or not, while the second group includes factors affecting which type of product the household will choose. In the first stage, the explanatory variables are income, family size, age of homeowner, number of long-distance trips, distance, and air temperature. The remaining variables including the regional dummies are used in the second stage (see NL-1 in Table 4). Considering that some of variables may affect both stages, we interchange the income, travel, distance, and air temperature variables with the electricity price, LPG price, and subsidy variables between the two stages (see NL-2 in Table 4). The estimation results are reported in Table 4.

\section{[Insert Table 4 about here]}

In the first stage, the results show that the variables income, family size, age, distance, air temperature, and subsidy policy play a role in the purchase decision. Consistently with the findings obtained with the multinomial logit models, factors such as income, size, distance, and temperature can promote the water heater usage of rural households. More precisely, the log-odds ratio increases by $2.65 \%$ when income rises by 1000 Chinese yuan $\left(0.0265^{* *}\right)$. The ratio increases substantially by $21.0 \%$ if one more person is added to a family $\left(0.210^{* * *}\right)$. These findings are consistent with the case of solar water heater diffusion in Taiwan, where economic status (disposal incomes and incentives) and population characteristics (household size) have been proven to be major barriers to installation decisions by households (Chang et al., 2009). The finding is also consistent with that by Ma et al. (2014), who found that a higher net income of rural residents can boost the application of solar water heaters significantly.

Information exchange is another significant factor in rural residents' purchase decisions. The effect is captured by the variable distance, whose coefficient is 0.646**. Lifestyle habits, represented by air temperature, are also an important factor. The estimated coefficient is $0.177^{* * *}$. According to Han et al. (2010), when the air temperature is below $-8{ }^{\circ} \mathrm{C}$, solar water heaters cannot work as the water in the pipe will freeze. Although energy prices are theoretically important factors for consumers in adopting water heaters based on fossil fuels (Michelsen and Madlener, 2016), neither electricity price nor LPG price is a significant factor in the process of the first decision for rural residents. Similarly to that obtained by multinomial estimation, the coefficient of policy variable is significantly positive (20.65***), indicating that the $13 \%$ price subsidy in rural China can substantially facilitate the diffusion of shower water heater. 
In the second stage, the sociodemographic factors income, awareness, and educational level are insignificant. This implies that income level can only determine the purchase behaviour and not the product type purchased. The findings are similar to those obtained by Goto et al. (2011), who found that the purchase of efficient water heaters compared with efficient ones is not related to family income in Japan. In the context of Spain and Tunisia, however, the situation appears to be different. According to a survey conducted by Ramos et al. (2016) in Spain, households with higher incomes and educational levels are more likely to invest in energy-efficiency improvements. Using survey data from Tunisia, Jridi et al. (2015) found that compared with traditional water heaters, both income and educational level exert a positive impact on the application of solar water heaters.

Among all the explanatory variables, solar radiation and electricity price play a role in the product type decision. Several interesting findings can be summarized. First, information exchange seems to be irrelevant for rural residents' decision in the second stage, although households have higher probability to install a water heater in the first stage if the family is located near a town. Note that we use village cluster standard error to treat with possible information spill over among residents from the same neighbourhood in a village. If we use traditional robust standard error, the three coefficients for variable distance are $-5.050 *, 1.990 *$ and $7.041 * *{ }^{6}$ The results simply imply that residents have more chance to deploy a solar water heater than their LPG and electric alternatives. The fact that these coefficients become insignificant by using village-clustered standard error further implies that instead of external information acquisition from the nearest town centre, the primary channel of information exchange may be the internal spillover among residents in the same village. Other related studies have also confirmed that information is an important factor. In Germany, for example, Michelsen and Madlener (2016) found that homeowners who are more informed have a higher probability of switching from a traditional heating system to a renewable one. This further highlights the importance of information provision (e.g., expected energy-saving effect, technical reliability, and tailored recommendations on technical parameters) in the adoption process of all kinds of solar water heaters.

Second, a higher electricity price will promote the substitution of an electric water heater for an LPG one $\left(0.374^{* *}\right)$. The coefficient of electricity price for solar water heaters is insignificant $(-0.0725)$ and that for LPG water heater is significantly negative $\left(-0.446^{* *}\right)$. It seems that for rural residents, a LPG water heater instead of a solar one tends to serve as a substitute for an electric product when electricity price goes up. In rural China, electricity price plays a limited role for rural residents in choosing low-carbon water heaters. This situation is different from those observed in industrialized countries. For example, Goto et al. (2011) and Michelsen and Madlener (2016) found 
that in Germany and Japan, respectively, an increase in energy price will enhance the probability of choosing energy-efficient water heaters, as a price increase promotes the consumer's consciousness of energy conservation, so a cost reduction in energy consumption becomes essential in the use of efficient appliances. One possible explanation for Chinese case is that electric heaters are installed in areas where the electricity prices are also higher. ${ }^{7}$ According to our survey, for example, the average electricity price for rural residents is 0.592 yuan per kWh in Hunan Province in 2013, the second highest among the 12 surveyed provinces. The coverage rate of electric water heater reaches $34.3 \%$, the third highest among the 12 provinces. Another explanation for the insignificant coefficient may be that in China the end-use electricity price is strictly regulated by the Chinese government. Residents within a province are charged the same electricity price, which is much lower than that for industries and keeps unchanged for years. Hence, residential price within a province demonstrates no variation and the cost-saving incentive of reducing electric bill is undermined.

Turning to the last variable, the $13 \%$ price subsidy exerts no differentiated effects on the three kinds of water heaters in the second stage, although it does matter for rural residents to make a purchasing decision of a water heater. This situation is somewhat different from cases in developed countries. In Japan, for example, when consumers know about the availability of financial support from the government, the purchase of energy-efficient water heaters with higher up-front costs increases significantly (Goto et al., 2011). In rural China, however, it seems that rural residents demonstrate a higher tendency to obtain grants when they purchase electric water heaters according to the results by multinomial logit model (Table 3). In the case of free-riders, more rural residents decide to purchase electric water heaters, which are much cheaper than solar water heaters, in advance and they enjoy the subsidy policy when it becomes available.

\section{Policy implications}

As a low-carbon product, solar water heaters deserve more policy attention compared to their alternatives that are fuelled by traditional energy sources in China. Potential policy interventions to popularize water heaters include awareness measures, command and control instruments, and market-based instruments (investment support and operating support) (Scarpa and Willis, 2010). However, the required change in consumption behaviours toward sustainable consumption cannot normally be achieved by force but can only be achieved with a voluntary approach such as an information-provision policy or economic incentive policies (Shen and Saijo, 2009).

A financial incentive policy is needed to accelerate the diffusion of solar water heaters in rural China. For a rational individual, the decision regarding whether to make an energy-efficiency 
investment requires weighing of the initial costs against the expected future capital savings (Gillingham et al., 2009; Wasi and Carson, 2013). According to a survey carried out in Zhejiang province, the up-front costs (average price and pipes costs) of solar water heaters amounted to 2250 yuan. This is much more expensive than the cost of purchasing an electric water heater $(833$ yuan on average) or a gas-fuelled water heater (560 yuan on average) (Han et al., 2010). Economic factors are considered the most important factors for residents regarding the use of solar water heaters in China (Yuan et al., 2011). In rural China, however, there is no specific incentive policy targeting the deployment of the low-carbon product (Li et al., 2013). The four-year subsidy policy nested in "Home Appliances Going to the Countryside" programme expired in early 2013 (Ma et al., 2014). This programme is not a specific policy for disseminating solar water heaters in rural China, as electric and LPG water heaters are also covered by the 13\% price subsidy policy. Compared with their alternatives, the much higher up-front costs of solar water heaters will still pose an obstacle to low-carbon investment among rural residents. According to the empirical results shown in Tables 3, the subsidy policy seems to be more effective for electric water heaters than for solar products. The much higher initial costs of solar water heaters may be a key factor, considering that the purchasing power of rural residents is generally limited. The support policy in China should be improved by explicitly targeting energy-efficient or low-carbon aspects of water heaters. Thus, a new programme targeting solar water heaters in rural China (probably a subsidy policy) ought to be issued in order to provide a financial incentive for rural residents to deploy the low-carbon product.

In addition, China has initiated a new round of electricity price reforms in 2015. One of the key targets is to shift the price-forming mechanism from a highly regulated structure to a marketbased pricing system (Zeng et al., 2016). In the case where the end-use price for residents can reflect its real costs and external environmental damages, the market incentive for investment in solar water heaters will be more likely to be effective. The usage of low-carbon products will be accelerated.

An information programme is also important for a low-carbon transition in rural China. For consumers who urgently need water heaters, insufficient information may be collected due to time and knowledge limitations. Then, inefficient investment decisions may be made. The best policy here is to improve the information set available to households who make purchases in emergency situations (Wasi and Carson, 2013). According to the empirical results of this paper, income is one of the key factors determining the application of water heaters in rural China, although it cannot determine which type of water heater is deployed. In China, there are more than 5000 solar water heater manufacturers, most of which are limited in production capacity and product quality (Han 
et al., 2010). To survive in the fiercely competitive market, they offer low-quality solar water heater products at very low prices, resulting in market disturbance. These aspects highlight the importance of provision of information regarding solar water heaters. To correct information market failures, the provision of information such as product quality, expected energy-saving effect, technical reliability, and tailored recommendations on technical parameters are necessary, and in this way the transition to low-carbon residential energy usage can be accelerated in rural China.

The findings of this paper also have some implications for the marketing policies of water heater manufacturers. For a water heater company, marketing efforts should be targeted at rural residents with relatively high incomes and young homeowners (not older than 60) who are not already equipped with shower water heaters. Regions with larger family sizes and/or higher temperature should be prioritized as the target market for popularizing solar water heaters. Also, villages near town centres should be targeted by water heater manufacturers when formulating marketing strategies, as the proximity to urban areas may increase the likelihood of consumers purchasing solar water heaters.

\section{Concluding remarks}

The adoption decision of durable goods such as water heaters is important because it probably fixes the hot-water-related fuel consumption type and pattern of a home for at least the next few years or even more than 10 years. Once a household has selected a solar water heater rather than one fuelled by traditional fuels, low-carbon consumption will be locked-in in the long run. We empirically investigated the choice patterns of households regarding water heaters, highlighting the widespread usage of solar water heaters in rural China. This makes this research relevant because the use of solar water heaters reduces not only the fossil fuel consumption and energy costs of households but also their $\mathrm{CO}_{2}$ emissions. Thus, it is of high relevance to gain a deeper understanding of homeowners' decision-making processes. From the empirical analysis using micro-level individual data from the questionnaire survey that was designed by our research team, we find considerable consumer heterogeneity regarding the preference for different types of water heaters among rural households. We show that there are different drivers behind the water heating adoption decision. In addition to sociodemographic characteristics (such as income, household size, and age), information availability is found to be a significant determinant of the homeowners' adoption decisions. Households located near urban centres have a higher probability of installing water heaters, particularly solar products. Another novel finding of this paper is that income, household size, and homeowner age only determine whether a household installs a water heater but do not affect which type of water heater is deployed. In rural China, electricity price plays little 
role in speeding up the green transition of energy systems because the price is unchanged for years and is too low (far lower than the industrial electricity price) to provide enough cost-saving incentives. The policy "Home Appliances Going to the Countryside" programme has been proven to be effective in promoting the penetration of water heaters in rural China. The importance of key determinants also differs between water heaters and groups of homeowners, implying that the water heater adoption decision is a rather complex process.

Three key policy and managerial implications can be drawn from this study, as follows: (1) Financial incentives: A subsidy programme targeting energy-efficient or low-carbon products like solar water heaters in rural China should be provided by the government to the rural residents; (2) Information disclosure: Provision of information regarding solar water heaters such as information on product quality, expected energy-saving effect, and technical reliability should not be ignored given that rural residents are imperfectly informed and hence make inefficient investments; and (3) Marketing perspective: For policy instruments aiming at promoting the success of solar water heaters, water heater manufacturers should take into account the heterogeneity of rural households, considering the regional variety in particular.

We conclude the paper with some comments on the potential and limitations of the present study. There are limitations related to the design of the questionnaire survey: (1) Due to budget considerations, we did not collect data from rural residents in all Chinese provinces, but instead chose 12 representative provinces from each administrative zone in China, which may affect the sample representativeness; (2) The survey period is limited to June 2014 to September 2014; in other words, our data are cross-sectional and not longitudinal, which prevented us from exploring the dynamic nature of rural households' preferences and attitudes towards a certain type of water heater given changing conditions like changes in energy prices or installation costs; (3) There are various types of water heaters on the market, and the solar-type water heaters themselves include two kinds: the solar-electric type and the solar only type. In this study, we did not attempt further classification to distinguish these two types but grouped them together as solar water heaters. There is also scope for further research. For example, peer effects have been recognized as one of the major drivers influencing nearly all individual decision-making (e.g., the diffusion of new technologies, the decision to adopt solar PV systems, etc.), as evidenced by a broad range of studies (Graziano and Gillingham, 2015; Manski, 1993; Rode and Weber, 2016; Towe and Chad, 2013). Mechanisms through which peer effects operate may include spatial knowledge spillover or information spread through contact, resource pooling, changes in preferences, and so on. Examining the peer effects in the residents' choices of water heaters in China could be one avenue of future research. 


\section{Acknowledgements}

We would like to thank Marcello Graziano (Central Michigan University), Xiaoyi Mu (University of Dundee) and anonymous reviewers for their very helpful and constructive comments. All the views expressed in this research and any errors are the sole responsibility of the authors. This research is supported by the Social Science Fund of Beijing (grant no.: 17YJC032), and the Fundamental Research Funds for the Central Universities and the Research Funds of Renmin University of China (project no.: 13XNJ017).

\section{Footnotes}

1 Without otherwise specified, the term "villages" used in this study refer to administrative villages, not natural villages. An administrative village typically include several natural villages.

2 For detailed information on the "Home Appliances Going to the Countryside" programme, please refer to Ma et al. (2014).

3 Note that the category "other water heaters" has been omitted from the discrete choice analysis as there were only a very small number of observations (see Fig. 3).

4 To better illustrate this result, we take the income coefficient of 0.0653 in the LPG case as an example. This coefficient satisfies the equation $\beta_{i}=\ln \left[\left.\frac{\operatorname{Pr}(y=L P G)}{\operatorname{Pr}(y=\text { base })}\right|_{x_{i}+1} /\left.\frac{\operatorname{Pr}(y=L P G)}{\operatorname{Pr}(y=\text { base })}\right|_{x_{i}}\right]$, where $\beta_{\mathrm{i}}$ represents the coefficient, $x_{\mathrm{i}}$ denotes income, and $\operatorname{Pr}$ is the probability function.

5 Because the estimated model does not satisfy the asymptotic assumptions of the Hausman test, the statistical values for some omitted categories are negative. We did not use this technique.

6 As a reviewer suggested, we use a more reasonable technique (i.e., village cluster standard error) to conduct statistical inference. Here we make some comparison with results by traditional robust standard error to analyse the primary channel of information spill over. To save space, we do not list the results by robust standard error in Table 4.

7 In general, this is the case but not for all provinces. For instance, according to our survey, Guangdong Province has a highest electricity price ( 0.681 yuan $/ \mathrm{kWh})$, but a low coverage rate of electric water heater (only 5.9\%).

\section{References}

Allcott, H., Greenstone, M. (2012) Is there an energy efficiency gap? Journal of Economic Perspectives 26(1): 3-28. 
Braun, F. (2010) Determinants of households' space heating type: A discrete choice analysis for German households. Energy Policy 38(10): 5493-5503.

Chang, K., Lin, W., Lee, T., Chung, K (2009) Local market of solar water heaters in Taiwan: Review and perspectives. Renewable and Sustainable Energy Reviews, 13(9), 2605-2612.

Chang, K., Lin, W., Lee, T., Chung, K (2011) Subsidy programs on diffusion of solar water heaters: Taiwan's experience. Energy Policy 39(2): 563-567.

Chang, K., Lin, W., Lee, T., Chung, K. (2016) Perspectives for solar thermal applications in Taiwan. Energy Policy 94(1): 25-28.

Decker, T., Menrad, K. (2015) House owners' perceptions and factors influencing their choice of specific heating systems in Germany. Energy Policy 85(1): 150-161.

Dubin, J., McFadden, D. (1984) An econometric analysis of residential electric appliance holdings and consumption. Econometrica 52(2): 345-367.

Gill, N., Osman, P., Head, L., Voyer, M., Harada, T., Waitt, G., Gibson, C. (2015) Looking beyond installation: Why households struggle to make the most of solar hot water systems. Energy Policy 87(1): 83-94.

Gillingham, K., Newell, R., Palmer, K. (2009) Energy Efficiency Economics and Policy. Annual Review of Resource Economics, 1(1), 597-619.

Goess, S., de Jong, M., Ravesteijn, W. (2015) What makes renewable energy successful in China? The case of the Shandong province solar water heater innovation system. Energy Policy 86(1): 684-696.

Goto, H., Goto, M., Sueyoshi, T. (2011) Consumer choice on ecologically efficient water heaters: Marketing strategy and policy implications in Japan. Energy Economics, 33(2): 195-208.

Graziano, M., Gillingham, K. (2015) Spatial patterns of solar photovoltaic system adoption: The influence of neighbors and the built environment. Journal of Economic Geography 15(4): 815-839.

Greene, W. (2011) Econometric analysis, seventh edition. NY: Pearson.

Han, J., Mol, A., Lu, Y. (2010) Solar water heaters in China: A new day dawning. Energy Policy 38(1): $383-391$.

Hausman, J., McFadden, D. (1984) Specification tests for the multinomial logit model. Econometrica 52(5): 1219-1240.

Jridi, O., Bargaoui, A., Nouri, F. (2015) Household preferences for energy saving measures: Approach of discrete choice models. Energy and Buildings 103(1): 38-47.

Liao, H., Chang, T. (2002) Space-heating and water-heating energy demands of the aged in the US. Energy Economics 24(3): 267-284. 
Lin, W., Chang, K., Chung, K. (2015) Payback period for residential solar water heaters in Taiwan. Renewable and Sustainable Energy Reviews 41(1): 901-906.

Li, W., Rubin, T., Onyina, P. (2013) Comparing solar water heater popularization policies in China, Israel and Australia: The roles of governments in adopting green innovations. Sustainable Development 21(3): 160-170.

Li, W., Song, G. J., Beresford, M., Ma, B. (2011) China's transition to green energy systems: The economics of home solar water heaters and their popularization in Dezhou city. Energy Policy 39(10): 5909-5919.

Liu, L., Wang, Z., Zhang, H., Xue, Y. (2010) Solar energy development in China-A review. Renewable and Sustainable Energy Reviews 14(1): 301-311.

Liu, Z. (2015) China's carbon emissions report 2015. MA: Cambridge.

Ma, B., Song, G., Smardon, R., Chen, J. (2014) Diffusion of solar water heaters in regional China: Economic feasibility and policy effectiveness evaluation. Energy Policy 72(1): 23-34.

Manski, C. (1993) Identification of endogenous social effects: The reflection problem. Review of Economic Studies 60(3): 531-42.

McFadden, D. (1978) Modelling the choice of residential location. In A. Karlqvist, L. Lundqvist, F. Snickars, and J. Weibull (eds.) Spatial Interaction Theory and Planning Models, 75-96, Amsterdam: North-Holland.

Michelsen, C., Madlener, R. (2012) Homeowners' preferences for adopting innovative residential heating systems: A discrete choice analysis for Germany. Energy Economics 34(5): 1271-1283.

Michelsen, C., Madlener, R. (2013) Motivational factors influencing the homeowners' decisions between residential heating systems: An empirical analysis for Germany. Energy Policy 57(1): $221-233$.

Michelsen, C., Madlener, R. (2016) Switching from fossil fuel to renewables in residential heating systems: An empirical study of homeowners' decisions in Germany. Energy Policy 89(1): 95-105.

NDRC (National Development and Reform Commission), 2013. Notice of exerting the leverage of price to facilitate the healthy development of solar photovoltaic industry (Fagaijiage [2013] No. 1638, in Chinese).

Ramos, A., Labandeira, X., Löschel, A. (2016) Pro-environmental households and energy efficiency in Spain. Environmental and Resource Economics 63(2): 367-393.

Rode, J., Weber, A. (2016) Does localized imitation drive technology adoption? A case study on solar cells in Germany. Journal of Environmental Economics and Management 78(1): 38-48.

Ruokamo, E. (2016) Household preferences of hybrid home heating systems - A choice experiment application. Energy Policy 95(2): 224-237. 
Scarpa, R., Willis, K. (2010) Willingness-to-pay for renewable energy: Primary and discretionary choice of British households' for micro-generation technologies. Energy Economics 32(1): $129-136$.

Shen, J., Saijo, T. (2009) Does an energy efficiency label alter consumers' purchasing decisions? A latent class approach based on a stated choice experiment in Shanghai. Journal of Environmental Management 90(11): 3561-3573.

Small, K. Hsiao, C. (1985) Multinomial logit specification tests. International Economic Review 26(3): 619-627.

Towe, C., Chad, L. (2013) The contagion effect of neighboring foreclosures. American Economic Journal: Economic Policy 5(2): 313-335.

Train, K. (2009) Discrete choice methods with simulation. Cambridge: Cambridge University Press.

Urban, F., Geall, S., Wang, Y. (2016) Solar PV and solar water heaters in China: Different pathways to low carbon energy. Renewable and Sustainable Energy Reviews 64(1): 531-542.

Wasi, N., Carson, R. (2013) The influence of rebate programs on the demand for water heaters: The case of New South Wales. Energy Economics 40(1): 645-656.

Wu, S., Zheng, X., Wei, C. (2017) Measurement of inequality using household energy consumption data in rural China. Nature Energy 2: 795-803.

Xinhua Net (2015) Enhanced actions on climate change: China's intended nationally determined contributions. Retrieved from http://news.xinhuanet.com/english/china/2015-06/30/c_134369837.htm on 10 April, 2016.

Yu, Y., Guo, J. (2016) Identifying the electricity saving potential in rural China: Empirical evidence from a household survey. Energy Policy 94(1): 1-9.

Yuan, X., Zuo, J., Ma, C. (2011) Social acceptance of solar energy technologies in China-End users' perspective. Energy Policy 39(3): 1031-1036.

Zeng, M., Liu, X., Li, Y., Peng, L. (2014) Review of renewable energy investment and financing in China: Status, mode, issues and countermeasures. Renewable and Sustainable Energy Reviews 31(3): $23-37$.

Zeng, M., Yang, Y., Wang, L., Sun, J. (2016) The power industry reform in China 2015: Policies, evaluations and solutions. Renewable and Sustainable Energy Reviews 57(1): 94-110.

Zhang, L., Jiang, J., Gao, W., Li, C. (2012) Study on word of mouth in the diffusion of low-carbon energy technology in rural areas: Taking the solar water heater as the example. Soft Science 26(4): 39-43 (in Chinese).

Zheng, X., Wei, C., Qin, P., Guo, J., Yu, Y., Song, F., Chen, Z. (2014) Characteristics of residential energy consumption in China: Findings from a household survey. Energy Policy 75(1): 126-135. 
Zheng, X., Wei, C., Song, F., Xie, L. (2016) Chinese household energy consumption report. Beijing: Science Press (in Chinese).

Zhu, J., Ruth, M. (2015) Relocation or reallocation: Impacts of differentiated energy saving regulation on manufacturing industries in China. Ecological Economics 110(1): 119-133. 


\section{Table 1}

Survey structure, definition of variables, and theoretical basis.

\begin{tabular}{|c|c|c|c|}
\hline Group & Variable & Definition & Theoretical basis \\
\hline $\begin{array}{l}\text { Water heater } \\
\text { usage }\end{array}$ & Water heater & $\begin{array}{l}\text { Usage (electricity, LPG, } \\
\text { solar, and others) and non- } \\
\text { usage }\end{array}$ & The dependent variable \\
\hline \multirow{5}{*}{$\begin{array}{l}\text { Socio- } \\
\text { demographic } \\
\text { characteristics }\end{array}$} & Income & $\begin{array}{l}\text { Total household income } \\
\text { divided by household size }\end{array}$ & $\begin{array}{l}\text { Water heaters are durable goods with high up-front costs (Han } \\
\text { et al., 2010). Financial considerations are one of the key } \\
\text { determinants in the decision-making process of consumer } \\
\text { adoption, especially for solar water heaters (Lin et al., 2015; } \\
\text { Wasi and Carson, 2013). }\end{array}$ \\
\hline & Size & $\begin{array}{l}\text { Number of household } \\
\text { members }\end{array}$ & $\begin{array}{l}\text { Household size largely determines the amount of demand for } \\
\text { hot water of a family (Goto et al., 2011). A larger size can } \\
\text { result in economies of scale (Ma et al., 2014). }\end{array}$ \\
\hline & Age & Age of homeowner & $\begin{array}{l}\text { Old people are typically risk-averse and tend to maintain their } \\
\text { traditional lifestyles (Michelsen and Madlener, 2012). They are } \\
\text { less likely to accept innovations such as installation of a new } \\
\text { water heater. }\end{array}$ \\
\hline & Awareness & $\begin{array}{l}\text { Awareness of electricity } \\
\text { conservation }\end{array}$ & $\begin{array}{l}\text { Energy-saving awareness may be important in selecting a low- } \\
\text { carbon durable (e.g., solar water heater) rather than an } \\
\text { environmentally unfriendly one (e.g., LPG water heater). }\end{array}$ \\
\hline & Education & $\begin{array}{l}\text { Educational status of } \\
\text { homeowner }\end{array}$ & $\begin{array}{l}\text { Lack of education can undermine the capacity to make an } \\
\text { investment decision and the ability to acquire knowledge to } \\
\text { operate a new product. }\end{array}$ \\
\hline \multirow[t]{2}{*}{$\begin{array}{l}\text { Information } \\
\text { exchange }\end{array}$} & Travel & $\begin{array}{l}\text { Frequency with which } \\
\text { family members travel } \\
\text { (only long-distance travel } \\
\text { where they cannot return } \\
\text { within a day) }\end{array}$ & $\begin{array}{l}\text { Rural residents can obtain more information about the sale } \\
\text { and usage of water heaters when they have the chance to go } \\
\text { into towns or cities (Zhang et al., 2012). However, if rural } \\
\text { residents spend most of their time in cities, the utility obtained } \\
\text { from using a water heater will shrink due to the idle period } \\
\text { during which the equipment is not used (Ma et al., 2014). }\end{array}$ \\
\hline & Distance & $\begin{array}{l}\text { Distance from the nearest } \\
\text { town/urban centre }\end{array}$ & $\begin{array}{l}\text { Water heaters are more popular in urban areas. Being located } \\
\text { near a town or urban centre may facilitate information } \\
\text { exchange on water heater usage. }\end{array}$ \\
\hline Lifestyle habits & Temperature & $\begin{array}{l}\text { Annual average air } \\
\text { temperature }\end{array}$ & $\begin{array}{l}\text { The air temperature will affect people's lifestyle habits such as } \\
\text { shower frequency and the desirable temperature of hot water. }\end{array}$ \\
\hline Natural resource & Solar & $\begin{array}{l}\text { The amount of solar } \\
\text { radiation }\end{array}$ & $\begin{array}{l}\text { Solar radiation is an essential condition for the use of a solar } \\
\text { water heating system (Han et al., 2010). }\end{array}$ \\
\hline \multirow{2}{*}{ Energy price } & $\begin{array}{l}\text { Electricity } \\
\text { price }\end{array}$ & $\begin{array}{l}\text { End-user electricity price } \\
\text { for household }\end{array}$ & $\begin{array}{l}\text { The end-use price of electricity mainly determines the } \\
\text { operating costs of an electric water heater. }\end{array}$ \\
\hline & LPG price & $\begin{array}{l}\text { Average retail price of } \\
\text { liquefied petroleum gas }\end{array}$ & $\begin{array}{l}\text { The retail price of LPG mainly determines the operating costs } \\
\text { of an LPG water heater. }\end{array}$ \\
\hline Policy variable & Subsidy & $\begin{array}{l}\text { Whether a subsidy nested } \\
\text { in the "Home Appliances } \\
\text { Going to the Countryside" } \\
\text { programme is available } \\
\text { when purchasing }\end{array}$ & $\begin{array}{l}\text { Due to high up-front costs, financial support has been proven } \\
\text { to be important in the deployment of solar water heaters (Lin } \\
\text { et al., 2015). The grant may also be important for households } \\
\text { to purchase other water heaters. }\end{array}$ \\
\hline
\end{tabular}




\section{Table 2}

Descriptive statistics

\begin{tabular}{|c|c|c|c|c|}
\hline Variable & Variable type & Item & Observation count & Percentage $(\%)$ \\
\hline \multirow{5}{*}{ Water heater } & \multirow{5}{*}{ Multi-categories } & Non-usage & 2245 & 65.95 \\
\hline & & Usage-Elec. & 389 & 11.43 \\
\hline & & Usage-LPG & 146 & 4.29 \\
\hline & & Usage-Solar & 576 & 16.92 \\
\hline & & Usage-Others & 48 & 1.41 \\
\hline \multirow{3}{*}{ Income (1,000 yuan/capita) } & \multirow{3}{*}{ Continuous value } & $(0,4]$ & 665 & 30.37 \\
\hline & & $(4,8]$ & 543 & 24.79 \\
\hline & & Above 8 & 982 & 44.84 \\
\hline \multirow{5}{*}{ Family size (capita) } & \multirow{5}{*}{ Discrete value } & 1 & 269 & 8.29 \\
\hline & & 2 & 1231 & 37.95 \\
\hline & & 3 & 676 & 20.84 \\
\hline & & 4 & 524 & 16.15 \\
\hline & & More than 4 & 544 & 16.77 \\
\hline \multirow[t]{2}{*}{ Age of homeowner } & \multirow[t]{2}{*}{ Binary categories } & $\begin{array}{l}\text { Above } 60 \text { (including) } \\
(=1)\end{array}$ & 1341 & 39.39 \\
\hline & & Under $60(=0)$ & 2063 & 60.61 \\
\hline \multirow[t]{2}{*}{ Energy-saving awareness } & \multirow[t]{2}{*}{ Binary categories } & $\begin{array}{l}\text { Usage of filament } \\
\operatorname{lamp}(=1)\end{array}$ & 1197 & 35.16 \\
\hline & & Otherwise $(=0)$ & 2207 & 64.84 \\
\hline \multirow{2}{*}{$\begin{array}{l}\text { Educational status of } \\
\text { homeowner }\end{array}$} & \multirow{2}{*}{ Binary categories } & Illiteracy $(=1)$ & 374 & 11.83 \\
\hline & & Others $(=0)$ & 2787 & 88.17 \\
\hline \multirow{2}{*}{ Number of trips in a year } & \multirow{2}{*}{ Binary categories } & {$[1,5](=1)$} & 835 & 24.53 \\
\hline & & Others $(=0)$ & 2569 & 75.47 \\
\hline \multirow{2}{*}{$\begin{array}{l}\text { Distance from the nearest } \\
\text { town centre }(\mathrm{km})\end{array}$} & \multirow{2}{*}{ Binary categories } & {$[0,1](=1)$} & 595 & 18.73 \\
\hline & & Others $(=0)$ & 2582 & 81.27 \\
\hline \multirow{2}{*}{$\begin{array}{l}\text { Average air temperature } \\
\text { (degrees Celsius) }\end{array}$} & \multirow{2}{*}{ Continuous value } & Below 15 & 1595 & 47.04 \\
\hline & & Above 15 (including) & 1796 & 52.96 \\
\hline \multirow{2}{*}{ Solar radiation } & \multirow{2}{*}{ Binary categories } & Rich zone $(=1)$ & 1527 & 44.86 \\
\hline & & Otherwise $(=0)$ & 1877 & 55.14 \\
\hline \multirow{2}{*}{$\begin{array}{l}\text { Electricity price (cents per } \\
\text { kilowatt hour) }\end{array}$} & \multirow{2}{*}{ Continuous value } & {$[45,55)$} & 2401 & 70.53 \\
\hline & & $(55,82]$ & 1003 & 29.47 \\
\hline \multirow{2}{*}{ LPG price (yuan per kilogram) } & \multirow{2}{*}{ Continuous value } & {$[4,8.5)$} & 1694 & 55.78 \\
\hline & & {$[8.5,11.5]$} & 1343 & 44.22 \\
\hline \multirow[t]{2}{*}{ Subsidy } & \multirow[t]{2}{*}{ Binary categories } & $\begin{array}{l}\text { Policy available when } \\
\text { purchasing }(=1)\end{array}$ & 468 & 13.75 \\
\hline & & Otherwise $(=0)$ & 2936 & 86.25 \\
\hline Total & & & 3404 & 100 \\
\hline
\end{tabular}


Table 3

Parameter estimates by multinomial logit model

\begin{tabular}{|c|c|c|c|c|c|c|c|}
\hline \multirow[t]{2}{*}{ Models } & & \multicolumn{3}{|c|}{ ML-1 (base: Not installed) } & \multicolumn{2}{|c|}{ ML-2 (base: Elec.) } & \multirow{2}{*}{$\begin{array}{l}\text { ML-3 (base: LPG) } \\
\text { Solar }\end{array}$} \\
\hline & & Elec. & LPG & Solar & LPG & Solar & \\
\hline \multirow{10}{*}{$\begin{array}{l}\text { Socio- } \\
\text { demographic } \\
\text { characteristics }\end{array}$} & income & $0.0266^{* *}$ & $0.0642^{* * *}$ & $0.0212^{*}$ & $0.0376^{* *}$ & -0.00534 & $-0.0430^{* * *}$ \\
\hline & & $(0.0120)$ & $(0.0156)$ & $(0.0123)$ & $(0.0172)$ & $(0.0115)$ & $(0.0147)$ \\
\hline & size & $0.225^{* * *}$ & $0.456^{* * *}$ & $0.160^{* * *}$ & $0.231 *$ & -0.0648 & $-0.296 * * *$ \\
\hline & & $(0.0724)$ & $(0.111)$ & $(0.0614)$ & $(0.128)$ & $(0.0661)$ & $(0.113)$ \\
\hline & age & -0.386 & $-1.032^{* * *}$ & $-0.530^{* * *}$ & -0.646 & -0.144 & 0.502 \\
\hline & & $(0.247)$ & $(0.393)$ & $(0.187)$ & $(0.448)$ & $(0.194)$ & $(0.405)$ \\
\hline & awareness & -0.0511 & 0.119 & 0.267 & 0.170 & 0.318 & 0.147 \\
\hline & & $(0.363)$ & $(0.339)$ & $(0.316)$ & $(0.413)$ & $(0.384)$ & $(0.411)$ \\
\hline & education & -0.209 & -0.0854 & 0.0299 & 0.123 & 0.238 & 0.115 \\
\hline & & $(0.470)$ & $(0.811)$ & $(0.282)$ & $(0.845)$ & $(0.432)$ & $(0.806)$ \\
\hline \multirow{4}{*}{$\begin{array}{l}\text { Information } \\
\text { exchange }\end{array}$} & travel & 0.319 & 0.285 & 0.305 & -0.0342 & -0.0144 & 0.0198 \\
\hline & & $(0.256)$ & $(0.292)$ & $(0.215)$ & $(0.360)$ & $(0.255)$ & $(0.299)$ \\
\hline & distance & 0.488 & 0.395 & $0.711^{* *}$ & -0.0924 & 0.224 & 0.316 \\
\hline & & $(0.388)$ & $(0.779)$ & $(0.330)$ & $(0.907)$ & $(0.379)$ & $(0.834)$ \\
\hline \multirow[t]{2}{*}{ Lifestyle habit } & temp. & 0.108 & $0.606^{* * *}$ & $0.184^{* *}$ & $0.497 * * *$ & 0.0752 & $-0.422 * *$ \\
\hline & & $(0.0799)$ & $(0.208)$ & $(0.0719)$ & (0.191) & $(0.0952)$ & $(0.204)$ \\
\hline \multirow[t]{2}{*}{ Natural resource } & solar & -0.424 & $-12.74 * * *$ & 0.514 & $-12.32 * * *$ & 0.938 & $13.25^{* * *}$ \\
\hline & & $(0.737)$ & $(1.129)$ & $(0.644)$ & $(0.854)$ & $(0.861)$ & $(1.147)$ \\
\hline \multirow[t]{4}{*}{ Energy price } & elec. price & $-0.0933^{*}$ & $0.103^{* *}$ & $-0.200 * * *$ & $0.197 * * *$ & -0.106 & $-0.303^{* * *}$ \\
\hline & & $(0.0477)$ & $(0.0512)$ & $(0.0711)$ & $(0.0660)$ & $(0.0759)$ & $(0.0803)$ \\
\hline & LPG price & -0.118 & -0.239 & $-0.248^{* *}$ & -0.121 & -0.130 & -0.00957 \\
\hline & & $(0.159)$ & $(0.179)$ & $(0.122)$ & $(0.208)$ & $(0.193)$ & $(0.217)$ \\
\hline \multirow[t]{2}{*}{ Policy variable } & subsidy & $20.89 * * *$ & $19.24^{* * *}$ & $20.31^{* * *}$ & $-1.651 * * *$ & $-0.573^{*}$ & $1.078^{*}$ \\
\hline & & $(0.478)$ & $(0.668)$ & $(0.288)$ & $(0.586)$ & $(0.294)$ & $(0.556)$ \\
\hline \multirow{4}{*}{$\begin{array}{l}\text { Regional } \\
\text { variable }\end{array}$} & east & 0.397 & -0.226 & -1.340 & -0.622 & $-1.736^{* *}$ & -1.114 \\
\hline & & $(0.467)$ & $(0.608)$ & $(0.867)$ & $(0.682)$ & $(0.868)$ & $(1.040)$ \\
\hline & west & -0.798 & -1.787 & $-2.134 * * *$ & -0.988 & -1.336 & -0.347 \\
\hline & & $(0.685)$ & $(1.240)$ & $(0.647)$ & (1.103) & $(0.980)$ & $(1.381)$ \\
\hline \multirow[t]{2}{*}{ Constant } & & 1.334 & $-20.27 * * *$ & $7.871^{* *}$ & $-21.60 * * *$ & $6.537^{*}$ & $28.14 * * *$ \\
\hline & & $(2.569)$ & $(3.696)$ & (3.931) & $(3.629)$ & (3.943) & $(4.779)$ \\
\hline Observations & & 1,757 & & & 1,757 & & 1,757 \\
\hline Pseudo R ${ }^{2}$ & & 0.365 & & & 0.365 & & 0.365 \\
\hline Log-likelihood & & -1122.6 & & & -1122.6 & & -1122.6 \\
\hline $\begin{array}{l}\text { Degree of } \\
\text { freedom }\end{array}$ & & 36 & & & 36 & & 36 \\
\hline
\end{tabular}

Note: (a) Superscripts ${ }^{* * *},{ }^{* *}$ and ${ }^{*}$ indicate statistical significance at the level of $1 \%, 5 \%$ and $10 \%$, respectively. (b) The values in parentheses are standard errors. (c) Because coefficients of alternative A based on B and for B based on A are opposite numbers, the paired coefficients are not presented here. 


\section{Table 4}

Parameter estimates by nested logit model

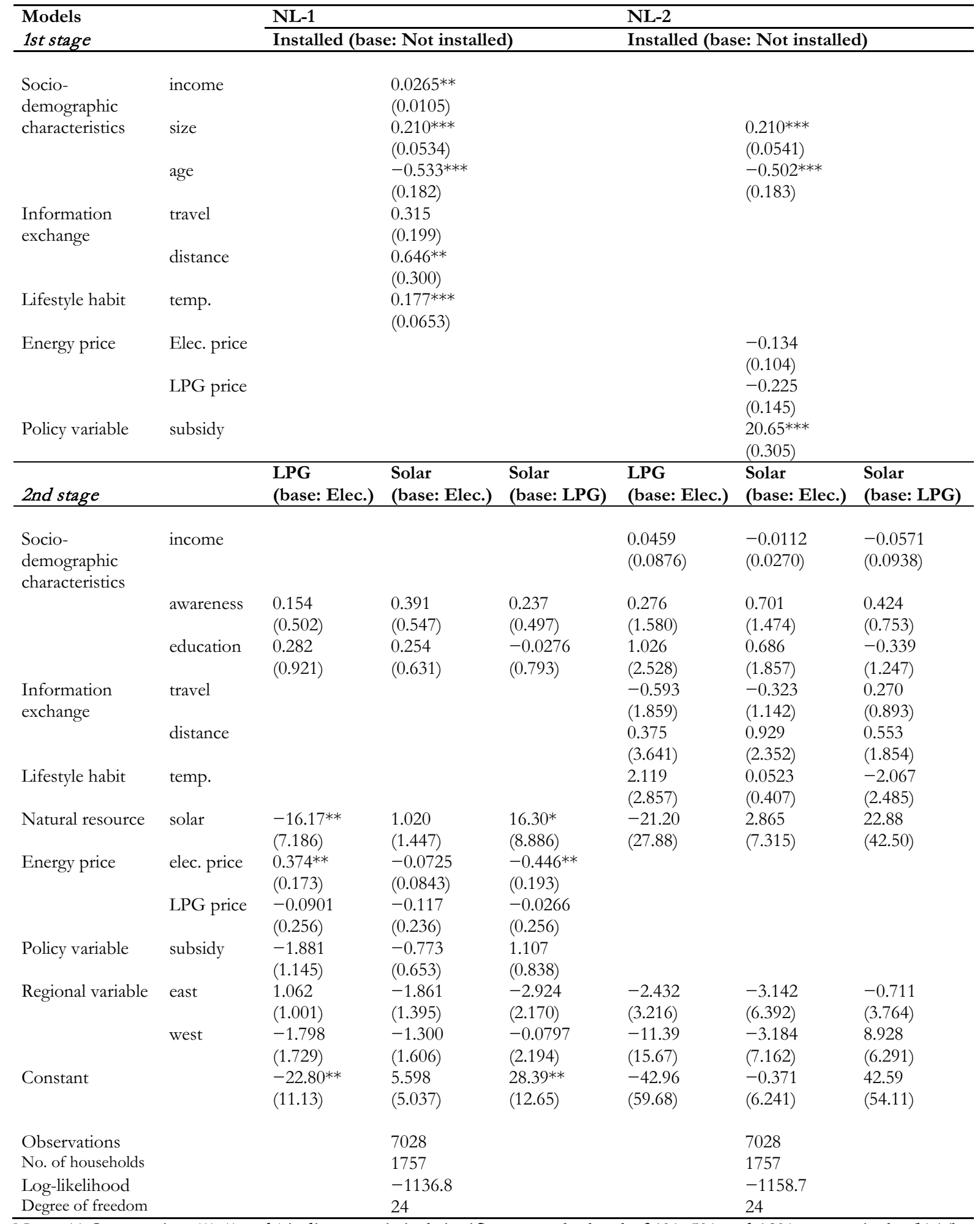

Note: (a) Superscripts ${ }^{* * *},{ }^{* *}$ and ${ }^{*}$ indicate statistical significance at the level of $1 \%, 5 \%$ and $10 \%$, respectively. (b) The values in parentheses are standard errors. (c) Because coefficients for alternative A based on B and for B based on A are opposite numbers, the paired coefficients are not presented here. 


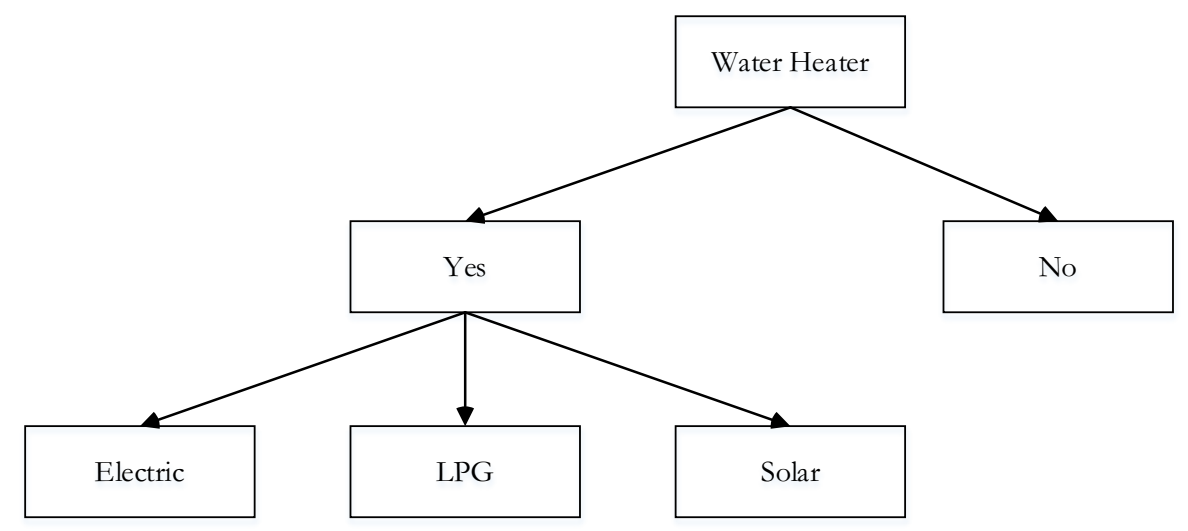

Fig. 1. The nested choice framework.

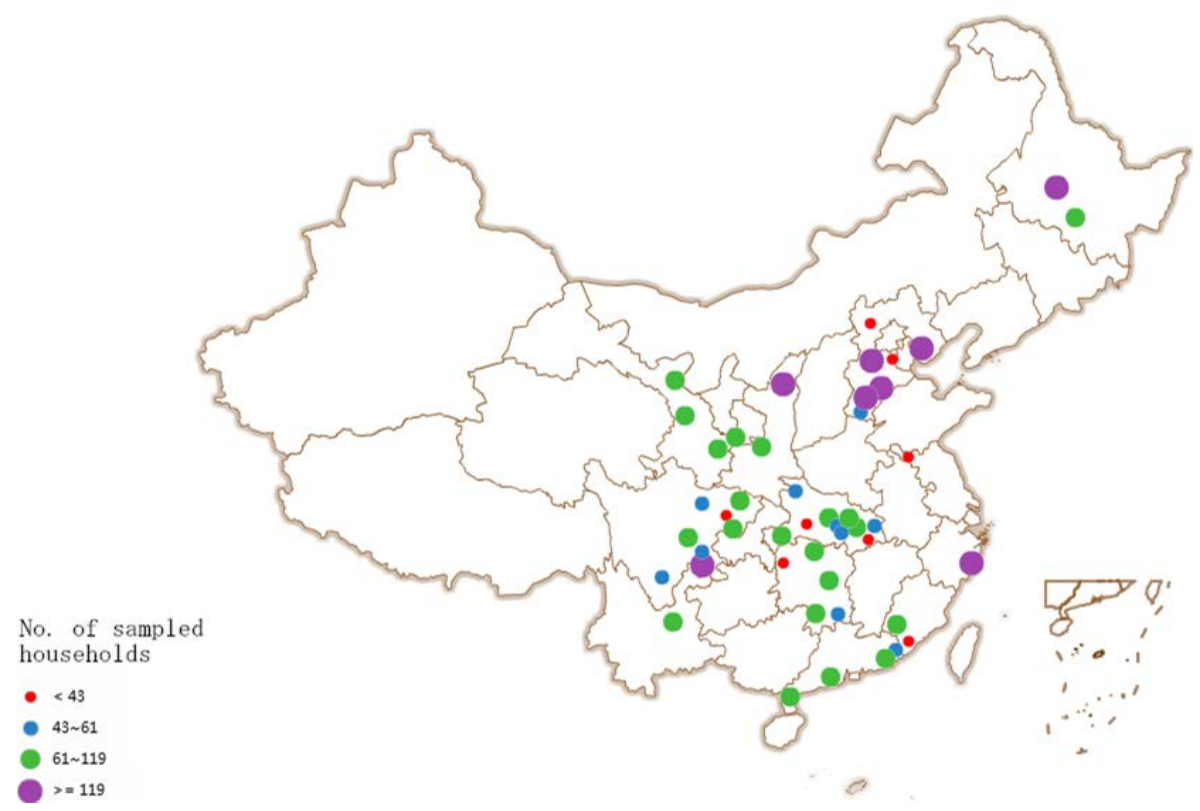

Fig. 2. Sample distribution.

(Notes: Figure was adapted from Zheng et al. (2016). Each dot in this map denotes the summed number of sampled rural households in each prefecture-level unit.)

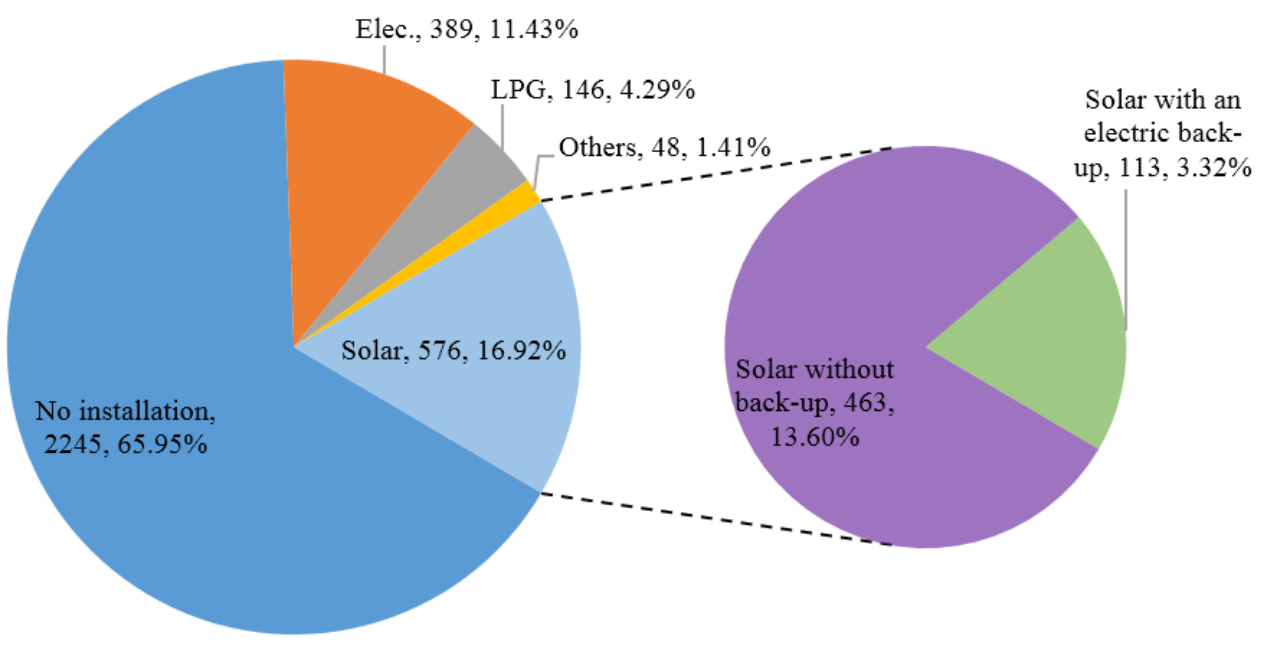


Fig. 3. Deployment rates of water heaters in rural China.

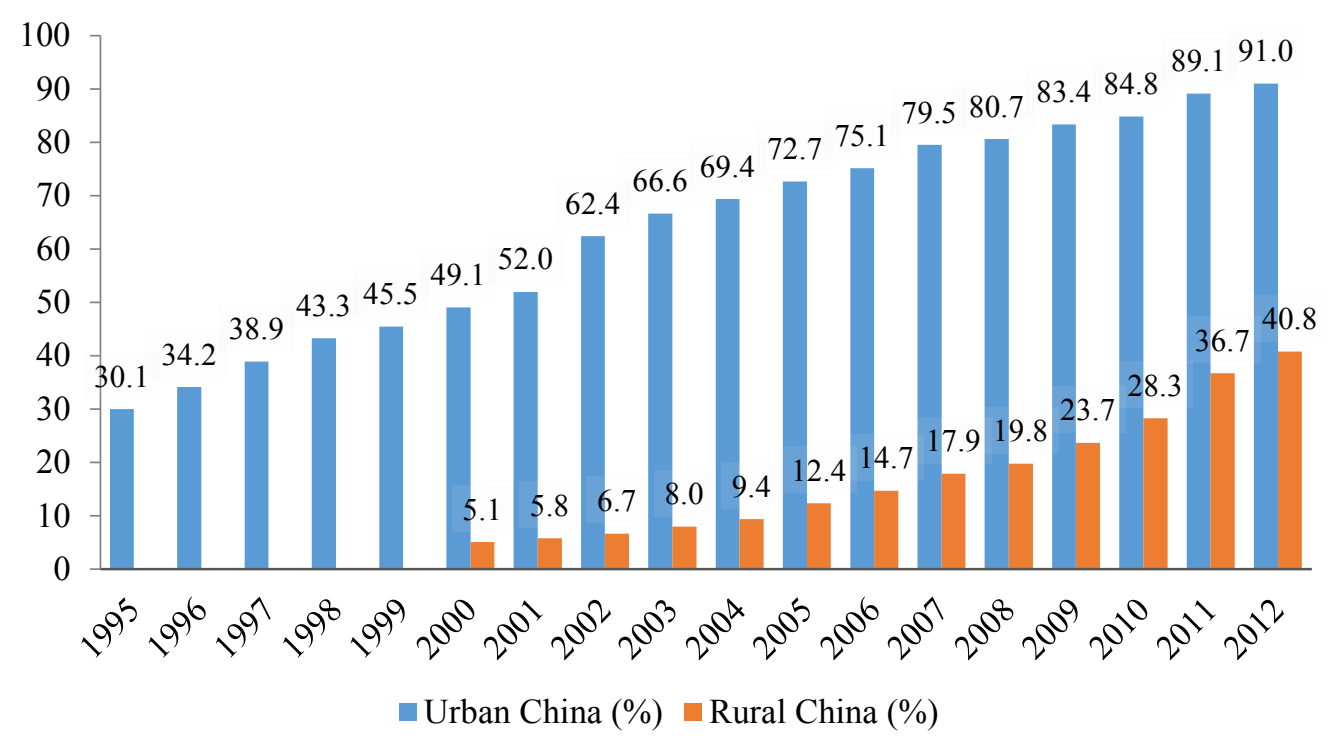

Fig. 4. Deployment rates of shower water heaters in urban and rural China. 